\title{
The evolution of markets under entry and standards regulation - the case of global mobile telecommunications
}

\author{
Harald Gruber (European Investment Bank and University of Siena) \\ and
}

Frank Verboven (University of Antwerp and CEPR)

\begin{abstract}
:
We analyze the effect of government policies on the evolution of global mobile telecommunications markets during 1981-1997. We obtain the following findings. (i) Countries that issue first licenses at later dates converge relatively slowly to early moving countries. (ii) The introduction of competition has a significant impact on the diffusion, especially after capacity expanded (digital phase). (iii) The timing at which second licenses are issued is important. Sequential entry is preceded by pre-emptive behavior and has a stronger impact than simultaneous entry. (iv) For the analogue technology, setting a single technological standard speeds up the diffusion. The results can be explained by structural characteristics of the industry, such as capacity constraints, consumer switching costs and network externalities.
\end{abstract}

Keywords: technology diffusion, entry regulation, standards and competing systems, capacity constraints, consumer switching costs, network externalities, pre-emption, mobile telecommunications.

JEL classification numbers: L1, L86, O3.

Mailing addresses:

\begin{tabular}{|l|l|}
\hline Harald Gruber & Frank Verboven \\
Projects Directorate & Department of Economics \\
European Investment Bank & University of Antwerp (UFSIA) \\
Boulevard Konrad Adenauer & Prinsstraat 13, \\
L-2950 Luxembourg & B-2000 Antwerpen, Belgium \\
Tel. 00352 43798606 & tel. 32-3-220-4877 \\
Fax 00352 43798831 & fax. 32-3-220-4799 \\
h.gruber@eib.org & frank.verboven@ufsia.ac.be \\
\hline
\end{tabular}




\section{Introduction}

In most industries governments intervene through various types of government regulation. In emerging industries, which are usually characterized by significant technological progress, there is usually little consensus on which policies to adopt. Among other issues, the debate focuses on how and when entry should be promoted, and whether technology standards should be imposed centrally or selected by the market forces in a decentralized way. Because of the lack of consensus governments typically take different policy options, and often change directions as experience accumulates. The aim of this paper is to assess empirically the effect of these public policies on the evolution of an industry. We consider the cellular mobile telecommunications services industry, a network industry that has been subject to heavy regulation of entry and technological standards.

The first policy dimension, the regulation of entry, has been an important issue in telecommunications markets during the last decades. The absence of competition in this industry has for a long time been defended by natural monopoly arguments, i.e. the presence of high fixed costs and the necessity for entrants to obtain access to the network of the incumbent. At least two factors have led to regulatory reform; see Laffont and Tirole (1999) for an overview of the theoretical literature. First, there was a growing concern with the inefficiencies caused by monopolies. These inefficiencies include insufficient incentives to reduce costs and to innovate, distorted price structures (too high prices, cross-subsidization, etc...) and underinvestment (as indicated by long waiting lists and poor service). Second, technological progress led to the belief that more than one firm could profitably operate in various segments of the telecommunications market. During the subsequent steps towards liberalization various questions had to be addressed, e.g. the regulation of access to 
competing networks. The liberalisation wave culminated in the inclusion of the telecommunications sector in the WTO framework in 1997. This means that the telecommunications markets are now open to competition in most of Western Europe, the US, Japan and many other countries.

The effects of entry in the cellular mobile industry are particularly interesting to analyze. The scarce resource to be allocated to the firms is the radio spectrum; technological progress permits greater efficiency in spectrum usage and thus increased capacity. Governments throughout the world have taken quite different options regarding the timing and the number of entry licenses. This provides interesting data for assessing the effects of licensing on the evolution of the industry. Our analysis considers the importance of the timing of first entry licenses, the effect of competition, and the role of timing of competition (simultaneous versus sequential entry), including pre-emption by incumbent operators. We consider the role of several structural characteristics of the industry, e.g. the evolving capacity constraints and the presence of consumer switching costs.

The second policy dimension we analyze is the regulation of technological standards. Various incompatible technological systems have been developed in the cellular mobile industry (most of them with the support of leading countries). Each system is subject to network externalities in that consumers value a system more the more users adopt it. The relevant policy question is whether governments should impose a single standard, or whether the markets should select a winning standard in a decentralized way; see Katz and Shapiro (1994) and Shapiro and Varian (1999) for surveys of the theoretical literature. Advantages of mandatory standards are that potential network externalities can be realized faster, and that users' technological uncertainty is reduced. Advantages from a decentralized approach are that there may be less risk of being locked in with inferior technologies and that incentives for innovation to better systems are preserved. Yet a counterargument is that also the 
decentralized approach may lead to lock in of inferior technologies. Despite the extensive theoretical literature, there exists no empirical work that compares the effect of imposing standards on the diffusion of a new technology with the effect of allowing multiple systems to compete. ${ }^{1}$ The cellular mobile industry offers an interesting opportunity to make such a comparison, since countries have followed quite different and changing policies regarding standards.

Our data set covers the entire evolution of the cellular mobile industry (1981-1997) ${ }^{2}$ for most countries in the worlds. Because of the drastic changes over time and the large variations across countries, the data set seems well suited to address the questions on the effect of alternative government policy options on the evolution of an industry. Industry evolution and the effects of entry regulation and standards are described in a logistic model of technology diffusion. To account for the heterogeneity of countries we have controlled for country characteristics such as income per capita, the size of the existing fixed network, and quality properties of the fixed network.

There is an increasing empirical literature on the diffusion of cellular mobile telecommunications. Most studies have considered the cellular mobile industry in individual or a restricted number of countries, focusing on market conduct (Parker and Röller, 1997; Nattermann, 1999), on the interaction with the fixed network (Cadima and Barros, 1999; Iha and Majumdar, 1999) or on the role of country characteristics (Ahn and Lee, 1999). De Kimpe, Parker and Sarvary (1998) use a global data set as in our study to estimate a diffusion model, but they focus on the role of macro-economic country characteristics and on forecasting the evolution of the industry. In contrast to these studies, we focus on the effect

\footnotetext{
${ }^{1}$ For an analysis of the presence of network effects, see Saloner and Shepard (1995). They do not directly compare competing systems with single standards.

${ }^{2}$ The exception is Japan, where cellular mobile telecommunications were already introduced in 1979.
} 
of public policies, i.e. entry regulation and imposing standards, controlling for various country characteristics. ${ }^{3}$

The paper is arranged as follows. Section 2 provides an extensive description of the most important technological and market features of the cellular industry. The knowledge of technological features is indispensable to understand the different trajectories the industry has undergone in the various countries. Section 3 describes the public policies regarding entry licensing and technology standards in the various countries. This also provides a first introduction to our data set. Section 4 describes the econometric model of diffusion, suitably adapted for a cross-country analysis. Section 5 presents and discusses the empirical results on the effects of entry regulation and standards on the evolution of the industry. Section 6 concludes and provides implications for public policy.

\section{The choice of the technological system}

\subsection{Brief history of mobile telecommunications before cellular}

Mobile telecommunications use radio waves, instead of wires, to connect users. The available portion of the radio frequencies in the overall spectrum is limited both by technology and regulation. Early pre-cellular mobile telecommunications systems had very limited capacity since they made use of the spectrum in a very inefficient way. Since there are many alternative uses for the radio spectrum (such as broadcasting or military applications), firms failed to convince governments to allocate a significant portion of the spectrum to mobile telecommunications (Kargman, 1978; Levin, 1971).

\footnotetext{
${ }^{3}$ Gruber and Verboven (1998) focus only on E.U. countries. They consider competition effects in less detail and do not look at standards. Instead they emphasize the importance of the capacity increase due to the transition from the analogue to digital technology.
} 
The earliest applications for mobile communications date back to the 1920s. In the U.S., the Detroit Police Department made the first experiments with "mobile" radio in 1921 (Calhoun, 1988). In Germany, the beginning of mobile telecommunications can be traced back to 1926 , when the first users calling from a train could be interconnected into the public (fixed) telecommunications network (Jung and Warnecke, 1998). Further developments of mobile telecommunications services were interrupted by the war.

After World War II, the civilian use of wireless telecommunications resumed and several industrialized countries independently developed mobile telecommunications systems. A major handicap for all these systems was that they required quite bulky and heavy user equipment. This implied that the mobile phones had to be fitted as car phones. Nevertheless, the users calling from mobile vehicles could be interconnected into the public network. The modes of accessing the public network were different from country to country. Some required manual interconnection, whereas Sweden developed fully automated switching right from the start (ITC, 1993; Mölleryd, 1997).

The early mobile radio systems were based on the same principles as radio or television broadcasting. They made use of high power transmitters located in base stations on top of the highest point in the coverage area. The transmitters operated at very low frequency levels of around $150 \mathrm{MHz}$. At such low frequencies, signals travel very far, so that a base station has a large coverage area, with a radius up to $80 \mathrm{~km}$. This has the advantage that only few base stations are required to cover a geographic area. However, at the same time, the few available frequency channels to support telephone conversations are locked up over a large area and can thus serve only a small number of users. For instance, in 1970 the Bell System in New York could support just 12 simultaneous mobile conversations. The $13^{\text {th }}$ caller was blocked (Garg and Wilkes, 1996). 


\subsection{The cellular concept}

The cellular concept was developed to achieve a more efficient use of the spectrum to support more subscribers. In contrast to the early systems, the cellular system makes use of low power transmitters, operating at much higher frequency levels, typically in the range of 400 to $900 \mathrm{MHz}$. At these frequency levels, signals do not travel so far, so that the base stations have a limited reach. Coverage of a large geographic area is obtained by dividing it into cells, with a base station in the middle of each cell. As a graphic illustration, one can draw a cell as a hexagon, surrounded by 6 adjacent hexagons. Many cells, with many base stations, are thus required to obtain full coverage of a large desired geographic area. This implies a considerable investment. The crucial advantage is however that the frequency channels to support telephone conversations are only locked over a limited cell area: the frequency channels can be re-used to support additional telephone conversations in other cells. This has the potential to greatly increase capacity. Note that, to avoid interference, adjacent cells have to operate on different sets of frequencies; the frequencies can thus only be re-used in non-adjacent cells.

If an existing cell has reached capacity limits, it can be further subdivided into additional cells. This is referred to as "cell-splitting". Cell splitting thus increases the scope for frequency re-use. This permits an increase of traffic handling capacity, of course at the cost of an additional investment in base stations. Cell splitting may be applied in a geographically selective manner: small cells are used for traffic-intensive urban areas and large cells are used in more suburban and less densely used areas. Cell splitting also allows the operator to spread the investment costs of a countrywide cellular network along with the growth in traffic. The system may start off with rather large cells. As customer traffic increases, the size of the cells may be decreased by creating new cells. There is no need to scrap the 
existing investment in the large-radius cell site equipment; the power of those transmitters may simply be powered down to fit within the new scale.

A cellular system would not work with frequencies below $400 \mathrm{MHz}$, since signals would travel too far for re-using frequencies. As the frequency increases, the attenuation of the signals increases. This affects both the maximum and minimum feasible cell sizes. For example, a $450 \mathrm{MHz}$ system is less suitable for urban areas with intense traffic because the minimum cell radius cannot go below $2 \mathrm{~km}$. Likewise, an $1800 \mathrm{MHz}$ system is good for urban areas but economically not justified for rural areas with little traffic since the maximum cell size of an $1800 \mathrm{MHz}$ system is about $7 \mathrm{~km}$.

Taken together, the base stations form the radio system. This is the most critical building block of a cellular system. On top of carrying traffic, the radio system must continuously monitor the position of the user to route the traffic to the base station within which range the user is located. As a user crosses a cell boundary, a new channel must be assigned quickly in order to maintain uninterrupted communication. This requires dedicated equipment, able to process large amounts of data.

The Bell Labs invented the cellular mobile telecommunications concept in 1947 in the US. The development was however left in an embryonic stage because the operation of moving telecommunications units required an enormous amount of data processing. Advances in microelectronics (the transistor, integrated circuits) made such tasks technologically feasible, but the costs remained prohibitively high for a long time. The large-scale production and sharply declining prices of semiconductors such as microprocessors and memories eventually made the cellular concept economically feasible by the 1970s. At that time only one barrier to its introduction remained. The frequencies in the 400-900 $\mathrm{MHz}$ range needed to be cleared; the frequencies used at that time by mobile telephone systems were too low for 
applying the frequency re-use principle on which the cellular concept is based. Regulatory reform to remove previous users (e.g. broadcasting) from the $400-900 \mathrm{MHz}$ range of the spectrum took several more years. The first licenses to cellular mobile telecommunication operators were eventually granted only at the beginning of the $1980 \mathrm{~s}$.

\subsection{Characteristics of alternative cellular systems}

One may distinguish between two types of technologies according to the way in which the signals are transmitted: the analogue (or first generation) and the digital (or second generation) technology. Analogue signals are radio waves that vary in frequency and amplitude. Digital signals consist of a stream of discontinuous pulses that correspond to the digital bits used in computers. Digital signals are divided into packets that are transmitted simultaneously with packets from other conversations (called "multiplexing"). This process leads to a significantly more efficient use of the spectrum, thereby improving spectrum capacity by a factor of 3 to 6 (Rappaport, 1996).

The digital technology not only greatly improves capacity. It has several additional advantages. It protects the transmission integrity because digital pulses are more easily regenerated by computers. High transmission integrity in turn allows cellular operators to offer an expanding array of new data services (e.g. short messaging services). Finally, the digital technology ensures privacy because digital signals cannot be eavesdropped.

Various systems were developed for both the analogue and digital cellular technology. These systems differ mainly in their ability to use the spectrum efficiently. Seven analogue systems found application worldwide, compared to four digital systems. For the third generation cellular technology, to be installed after 2002, it is likely that a single worldwide standard 
emerges, or at least a family of compatible systems ${ }^{4}$. We now describe the technological characteristics of the various analogue and digital systems in more detail.

\section{Analogue cellular systems}

The large number of analogue systems in the early days of the cellular industry may be explained by the fact that most countries viewed cellular telecommunications as just an additional new business of the state-owned telecommunications monopoly. Thus, the development of the cellular network was a means of honing the innovative capabilities of national equipment suppliers. Some technological features of the various analogue systems are summarized in Table 1. Among the most important differences between analogue systems are the frequency range allocated for transmission and the bandwidth of a channel. The frequency range and the channel bandwidth determine the number of speech channels. The channel bit rate (in 1000 bits per second) indicates the density of the bit-stream. The spectral efficiency is the number of bits that can be sent per second over a channel of a given bandwidth, i.e. the channel bit rate divided by channel bandwidth. This ratio is used as a general measure of the efficiency of a system.

(Insert table 1 about here)

- NTT: Japan introduced this as the first cellular system worldwide in 1979. Table 1 shows that this is a very inefficient system (in terms of channel bit rate at a given bandwidth).

- NMT: This is the second cellular system introduced in 1981. It was jointly developed as NMT 450 by the Scandinavian countries Denmark, Finland, Sweden and Norway and then adopted as the single cellular standard for these countries. Around 1983 there were

\footnotetext{
${ }^{4}$ For a discussion of the technological options, see Webb (1998) and Gruber and Hoenicke (1999).
} 
already signs of capacity shortages. The NMT 900 was subsequently introduced in 1986. Since the NMT 900 system had been assigned more spectrum and needs as smaller channel width, the number of channels could be increased from 180 to 2000 . Furthermore, the system was specified as a small-cell cellular system whereby cells in each transmission area were to be split further into so called micro-cells. This enabled the construction of smaller mobile phones, as signals had to travel a shorter distance. From the point of view of the equipment producers, the NMT 900 specifications did include innovative features, but these were mostly related to the software requirements of the equipment that had already been developed for the NMT 450 system.

- AMPS: This system was invented in the U.S. already in 1970, after the FCC decided to allocate spectrum for mobile services around the $800 \mathrm{MHz}$ frequency. But it took a further 12 years before the decision to license the system was taken. During these years there was a heavy regulatory debate concerning the breaking up of the Bell system and the number of licenses to be allocated in each geographical area.

- TACS: This system, introduced in 1985, is a British adaptation of the AMPS standard to comply with the different frequency allocation prevailing in Europe (Appleby, 1991). The two systems are not compatible, but many specifications are similar and thus the equipment suppliers could use the same network specification.

- C-450: This system was first adopted in Germany after the failure to reach an agreement on a joint procurement with France (Müller and Toker, 1994). The system was developed by Siemens, the dominant national telecommunications equipment supplier in Germany. It was technically complex and showed little regard for user needs. C-450 found adoption only in Portugal and South Africa. Consequently, it could not attain the benefits from economies of scale as the systems in the U.S., the U.K. and the Scandinavian countries. 
- RC2000 and RTMS: These systems, adopted by France and Italy respectively, are sometimes referred to as quasi-cellular services, because there was limited ability for hand-over from one cell to another. Both countries later adopted additional systems: the NMT system in France (Manguian, 1993) and the TACS system in Italy (Guerci, 1998).

Figure 1 illustrates the differences in popularity between the various analogue systems. AMPS had the largest number of national networks. On the basis of spectral efficiency, it also ranks first. NMT, which is one of the least efficient systems, obtained the largest number of networks in Europe and ranks second worldwide. The TACS system ranks third in terms of number of networks. The C-450 system, which is technically quite sophisticated and efficient, was adopted in only two countries besides the home country Germany. The other systems were not adopted outside their home countries.

This comparison shows that the most successful systems occur if the domestic market was sufficiently large (AMPS for the U.S.) or if the governments coordinated with other countries (NMT for Scandinavian countries). The large diffusion of TACS follows from the fact that it is an adaptation of AMPS to another frequency band. The examples of NTT, C450, RTMS and RC2000 show that the national market alone was usually too small to economically support the development of additional incompatible systems.

\section{Digital cellular systems}

The number of digital cellular systems is much lower than the number of analogue systems, mainly because the European countries this time adopted GSM as a standard. Different competing systems were introduced in the U.S. and Japan. Table 2 provides a summary of some technological features of the various digital systems.

(Insert table 2 about here) 
There are two large families of digital cellular systems, characterized by their so-called access systems: TDMA and CDMA. Their features will be discussed in the following. The time division multiple access (TDMA) technology is the cornerstone for most digital systems. The TDMA technology splits a frequency channel into $\mathrm{n}$ different time slots, and allocates each user one time slot. Thus n calls can travel over one cellular channel, compared to only one under an analogue system. The three incompatible TDMA systems that found application are: GSM, DAMPS and PDC. An alternative to the TDMA technology is the code division based multiple access (CDMA) technology. The CDMA technology allows all users to share the whole frequency channel, but the signals carry a code to distinguish them from each other. The advantage of CDMA is that the same set of frequencies can be used in every cell, due to a peculiar ability to discern signals from noise ${ }^{5}$. This provides potentially great improvements in capacity. The system using the CDMA technology is IS-95.

- $\mathrm{GSM}^{6}$ : This system was developed as a coordinated effort by the European countries. The GSM standard has a spectral efficiency that is about four times higher than the most efficient analogue system.

- JDC: This is the system introduced as a national standard in Japan. The intention was to establish this system as a regional standard under the name Pacific Digital Cellular (PDC). This failed as no other country outside Japan adopted the system.

- DAMPS: This system was introduced by the U.S first under the name IS-54. The objective was to ensure a smooth transition of the prevailing analogue standard into a digital system. The system divides an analogue channel into three parts, thereby tripling

\footnotetext{
${ }^{5}$ Whereas with TDMA each user of a transmission channel is allocated a time slot, with CDMA all users share the whole channel, but their signal carry a code to distinguish them from each other. To use an analogy: TDMA is like everybody speaking sequentially one after another; with CDMA everybody speaks at the same time but with a different voice pitch that can be unambiguously captured by the receiver.

${ }^{6}$ GSM stands for Global System of Mobile Communications. For an institutional history of GSM, see Garrard (1998) and for a detailed technical description Redl et al. (1995).
} 
capacity. It turned out that IS-54 had a worse speech quality in the digital mode compared to the analogue mode. This was however improved with a later revision of the system, now also knows as IS-136. DAMPS has a higher spectral efficiency than GSM.

- IS-95: This system is based on the innovative CDMA technology, developed and patented by the U.S. firm Qualcomm under the name cdmaOne. Performance comparisons between systems are difficult. However, a widely shared guess of the capacity advantage of CDMA over TDMA is about 30\%. (Garg and Wilkes, 1996; Webb, 1998).

Figure 2 shows the differences in popularity between the various digital systems. GSM was the first to be introduced at a large scale in many countries and since then it has dominated the market. In 1997, of the 40 million digital subscribers worldwide, more than 80 per cent were GSM subscribers. Of the competing systems, DAMPS had a timing advantage over CDMA-IS95, as well as the backward compatible installed base of AMPS. However, CDMA is spreading more rapidly, especially in Asia, where it has won the race against JDC.

(insert figure 2 about here)

\section{Government licensing policies}

Government licensing policy in mobile telecommunications has various dimensions. First, the government needs to decide whether to set a single national (or international) standard, or whether to allow multiple technological systems to compete. Second, the government has to decide to how many operators licenses will be granted. This also involves an important decision with respect to the timing of first and additional licenses. Third, the government needs to decide how to grant licenses. In the early days of mobile telecommunications, licenses were often granted on a first-come-first-serve basis. With the introduction of the 
cellular technology, the first licenses were frequently granted by default to the incumbent fixed operators. Additional licenses were either granted through an auction, or through an administrative tender procedure (or "beauty contest"), possibly including a license fee ${ }^{7}$.

In our study we focus on the first and the second dimensions of the licensing policies: a single standard versus competing systems; and timing of first and additional licenses. The room for discretionary policy is limited by the available spectrum capacity and by the technological options. The policy decisions are described in the $2 \times 2$ policy matrix on Table 3. The columns denote the number of countries that opted for a single standard or for multiple competing systems. The rows denote the number of countries that admitted one monopoly operator or competing operators. The matrix distinguishes between the analogue and the digital technology (reference year: 1997). The policy matrix will be used in our discussion of the government licensing policies in the subsections below.

\subsection{Multiple systems or single standards}

In markets without network effects, it seems to be unambiguously desirable to allow multiple competing technological systems. In contrast, in markets with network externalities there are both advantages and disadvantages to having multiple systems rather than a single standard. The presence of (strong) network externalities typically leads to "tipping" markets, where the winning technology takes the whole market. Should the government intervene in this race by imposing a single standard? Or should the markets decide themselves on which standard will eventually "win"? The theoretical literature does not provide an unambiguous answer to these questions (for an overview, see Katz and Shapiro, 1994). Advocates of government intervention argue that imposing a single standard makes it possible to realize network externalities faster, and reduces the technological uncertainty among consumers. Advocates

\footnotetext{
${ }^{7}$ For a survey of the different allocations mechanisms see Genty (1999).
} 
of free markets point out that a decentralized approach is the best guarantee to promote technological progress to develop even better technological systems, and reduces the risk of being locked in into an inferior technology promoted by the government ${ }^{8}$. A counterargument is that free markets may also lead to lock in into inferior outcomes, thereby necessitating government intervention to cope with this network externality 9 .

To which extent are network externalities in fact present in cellular telecommunications markets? Note that mobile users can call any other mobile user, whether or not they are subscribers to the same system. ${ }^{10}$ The main sources of network externalities arise from the fact that mobile users can only use their handset within the areas that support their technological system. Consumers who only use their handset nearby their homes would prefer a single system within the area where they live, since this would allow them to easily switch to a competing operator (without a need to buy a new handset). Yet such consumers would not care whether competing operators in other areas also offered the same system. Consumers who roam across the country would gain from having a single, nation-wide system. This allows them to use their handset wherever they are located. Consumers who frequently travel abroad would also gain from having an international standard. Thus depending on the mobility of consumers, network externalities are local, national, or even international in scope. In addition to reducing consumer switching costs and creating roaming possibilities, the presence of a single technological system also has the traditional advantage of exploiting economies of scale in the manufacture of equipment.

\footnotetext{
${ }^{8}$ An example is high definition television in Japan, where the government promoted an analogue standard neglecting the fact that the worldwide evolution would be toward digital technology (Shapiro and Varian, 1999).

${ }^{9}$ The typical example reported in the literature is the QUERTY keyboard winning over the allegedly superior Dvorak keyboard. But Liebowitz and Margolis (1999) confute these arguments after careful investigation of the case and claim more generally that the set of at the same time theoretically possible and empirically relevant examples of market failures in picking standards is actually empty.

${ }^{10}$ Yet there may be network externalities induced by price discounts for calling users on the same network.
} 
In practice, Varian and Shapiro (1988) argue that network externalities in the cellular mobile industry are "strong, but not overwhelming". For example, even if consumers are locked in into one system, they can switch to other systems at a discount in exchange for signing service contracts. They conclude that the market is not especially prone to tipping. And indeed, in none of the cases where competition between systems was allowed there was a system that eventually cornered the market fully and became the de facto standard (e.g. the U.S. digital cellular market still supports three systems).

What is the relative importance of competing systems versus standards for cellular telecommunications? Table 3 shows that of the 118 countries that adopted an analogue cellular system, 105 opted for a single standard, and 13 for competing standards. A quite similar picture obtains for the countries that adopted a digital system. Of the 87 countries, 79 opted for a single standard, and 8 for competing standards. Thus there is a fairly constant fraction of countries (about 10\%) that adopts multiple systems.

Has there has been an evolution of the standard selection mechanism over time, in particular passing from analogue technology to digital technology? Figure 3 illustrates the evolution of the fraction of adopting countries that have chosen a single standard. The figure shows that for both analogue and digital technologies there is a single standard during the first years. While multiple systems of analogue technology start to appear only after 8 years, this already happens after two years with digital technology. However, the share of the countries with multiple systems seems to stabilize around $10 \%$ for both technologies.

(Insert figure 3 about here)

Experiences in some individual countries 
The full economic benefits of competition among systems accrue only if there is also competition among firms. Mobile telecommunications in the early phase was in many countries a monopoly activity and therefore standard setting mainly consisted in establishing a technical specification for suppliers and possibly to induce competition among them. Nevertheless there are cases were a monopoly firm uses multiple systems, as will be discussed later. In the following, some individual country cases are presented to illustrate the determinants of the decisions on which system to adopt.

During the analogue period, the European countries followed an uncoordinated approach, which resulted in a proliferation of systems. Some of these systems did not even find an application outside the home country. As a result, pan-European roaming possibilities were mostly limited. Notable exceptions are the Scandinavian countries whose coordinating efforts led to the NMT system with the possibility of roaming across Scandinavia. This system was conceived as an open system, whose specifications were available free of charge to anyone interested and capable of supplying the necessary equipment. However, the Scandinavian equipment producers had already gained valuable insights into the technical details of the emerging system through the various formal and informal contacts established during the drafting of the standards (Palmberg, 1998; Mölleryd, 1997). All Central and Eastern European Countries introduced NMT systems, though late, under monopoly and without roaming facilities. The active promotion thus resulted in a relatively large poplarity of the NMT system, illustrating that a centralized approach not necessarily leads to the most efficient systems, in terms of an efficient use of the scarce spectrum.

In contrast to Europe, the U.S. introduced a single standard, the AMPS system, with nationwide roaming possibilities. This single standard promoted the consolidation of the industry where most of cellular operators not related to the Baby Bells were acquired or merged into 
nationwide operators. The AMPS system became also the most widely used system in Central and Southern America.

Japan was the first country to introduce cellular systems in 1979. The NTT technology was entirely an in house development of the incumbent telecommunications monopoly. The technology was inefficient and there was a slow diffusion. The introduction of a second system was imposed by the US in the attempt to resolve trade friction in the high technology industries that were negatively affecting the political relations between the two countries ${ }^{11}$. This coincided also with an opening up of the cellular market by establishing a monopoly.

When the digital technology emerged, the demand for a single standard in Europe was strong. The launch of digital cellular coincided with the effort to complete the Single Market of the E.U. Thus ensuring a level playing field for all competitors, as entailed by a common standard, was perceived to contribute to this policy goal. The European Commission spent considerable efforts to follow a coordinated approach this time, in collaboration with the state-owned telecommunications operators and the equipment industry. The coordinating efforts resulted in the introduction of the GSM system as the single European standard. Although the GSM technology is seen as a relatively inefficient technology, the fact that it was the first digital technology to be adopted probably gave it a large advantage over the competing systems. In Japan, there was a similar desire for a single standard, in the context of two existing incompatible analogue systems already installed (NTT and TACS). This led to the introduction of the JDC system as a digital standard in Japan.

\footnotetext{
${ }^{11}$ The US argument in the dispute was that Japanese companies could supply handsets for the AMPS and TACS standard worldwide, but foreign companies had little incentives for developing handsets for NTT technology given that this would only serve the Japanese market. The US wanted Japan to adopt a system that is compatible with internationally more widespread systems. Thus Japan licensed a second cellular operator using TACS technology (Tyson, 1992).
} 
In the U.S. the desire for a single digital standard was not so strong, since with AMPS they had already set a standard for the analogue technology. The U.S. cared more about backward compatibility so that existing analogue users would not be stranded. The result was three different competing systems. The first system, DAMPS, offered backward compatibility with AMPS. In this sense the system enhances, rather than replaces, the existing analogue system, allowing operators to gradually phase out AMPS as more users accept digital phones. The second system was the GSM system, which uses capacity less efficiently, but has the advantage of compatibility with the European standard, which has become the most popular system worldwide. The third competing system was the IS-95 system, based on the new CDMA technology. When the theoretical capacity gains in the order of 20 times over existing digital systems were first announced, there was suspicion of strategic product preannouncement to slow down the diffusion of the already developed TDMA system. Yet IS95 developed itself from an elegant theoretical possibility to a credible competitor after the commitment of large US cellular firms such as Bell Atlantic and Nynex to adopt this system. Thus a standard battle between the CDMA and TDMA technology ensued. However, it is now clear that the family of third generation cellular telecommunications, as promoted by the standardization body International Telecommunications Union will be based on CDMA technology. This suggests a leapfrogging pattern in technological innovation with the U.S. and Europe alternating the leadership: the most popular first generation standard AMPS of the U.S. was supplanted by the second-generation standard European GSM which again is overtaken by CDMA for the third generation.

\subsection{The timing and the number of licenses}

Countries have been quite heterogeneous in their decisions and timing to issue first and additional licenses. The policy matrix on Table 3 shows that of the 118 countries that 
adopted an analogue cellular system, 88 countries had chosen for a monopoly (of which 83 with a single standard and 5 with multiple systems) and 30 countries had chosen an oligopoly. This relationship is reversed for the digital technology. Of the 87 countries, only 39 have a monopoly, whereas 48 have an oligopoly. This indicates a worldwide trend towards oligopoly with the introduction of the digital technology. This is also confirmed in Figure 4, which shows the evolution of the fraction of adopting countries with a monopoly for mobile telecommunications. For the analogue technology there was an eight-year period during which all the adopting countries had a monopoly. Then the share of monopoly countries started to decline. For the digital technology the pattern is the opposite. During the first two years there was no monopoly setting at all. Monopolies then set in and reached a peak of about $50 \%$ after 3 years. Afterwards the fraction of monopolies started to decline.

\section{(Insert figure 4 about here)}

An explanation for this pattern relates to the differences in capacities during analogue and the digital periods. The countries that introduce first licenses early have a strong preference for a wide diffusion of the new technology. Yet during the early years of the analogue technology capacity was still very much constrained, so that the countries would gain little from introducing competition. With the introduction of the digital technology, capacity expanded drastically. The early moving countries then had much to gain from introducing competition immediately. In contrast, the late-coming countries, with a presumably lower preference for a widespread diffusion, had a lower incentive to introduce competition, hence the peak in the fraction of monopolies after several years.

Capacity thus seems to be a first crucial factor in explaining the effects of competition on the diffusion of mobile penetration. When capacity is constrained, as under the analogue technology (especially during the early years), the effects of competition on mobile 
penetration are likely to be modest. The effects of competition are potentially much larger under the digital technology when capacity constraints are relaxed.

In addition to capacity, consumer switching costs are a potential determinant of the competition effects in the mobile industry (see e.g. Valetti and Cave, 1998). For example, mobile operators frequently offer long-term contracts to consumers, thereby artificially creating lock-in ${ }^{12}$. In a one-period context, switching costs (like product differentiation) tend to soften competition between operators. In a dynamic setting, switching costs may induce firms to compete more aggressively for market share during the early phases of competition. The presence of switching costs gives rise to some testable predictions. First, switching costs can explain how the timing of competition affects the diffusion of innovation. When entry is simultaneous, operators obtain more or less symmetric market shares, allowing them to compete rather softly. In contrast, when entry is sequential, the entrant has to compete aggressively to obtain customers from the installed market share of the incumbent firm. ${ }^{13}$ One may thus expect stronger effects on mobile competition when competition is introduced sequentially, than when competition is introduced simultaneously (though in the latter case the competition effects obviously take place at an earlier date). Second, when entry is sequential, switching costs may lead to pre-emptive behavior. The incumbent firm may start pricing or advertizing agressively already in the period prior to entry.

In our empirical analysis in the next sections, we consider the effects of competition on mobile penetration, and the role played by capacity (analogue versus digital), the timing of entry (simultaneous versus sequential) and pre-emption. In the remaining of this subsection we take a closer look at the experiences in some individual countries.

\footnotetext{
${ }^{12}$ As mentioned before, switching costs are further enhanced when there are multiple systems, forcing consumers to purchase a new handset when they want to switch operators.

${ }^{13}$ See Klemperer (1992) for a model of sequential entry in the presence of switching costs. Van De Wielle and Verboven (1999) compare simultaneous and sequential entry in a model with switching costs. Gruber (1999)
} 


\section{Experiences in individual countries during the analogue period}

Most countries in Western Europe granted the first analogue licenses to a subsidiary of the state-owned telecommunications monopoly. Domestic equipment suppliers were selected to foster "national champions". The main exception was the U.K. where a duopoly was installed. France and Sweden permitted entry of a second firm into the market for analogue cellular services at a later stage. The monopolies often resulted in inefficient procurement: firms adopted less advanced and more expensive network equipment than was commercially available in the international marketplace. The Eastern European countries were relatively latecomers for mobile services. In all countries mobile services were introduced after 1990 as a monopoly (see Gruber, 1999).

In Japan the cellular service was a monopoly held by NTT from 1979 to 1985. Regional duopolies were established starting from 1986, with NTT licensed nationally. One license was given to Nippon Ido Tsuschin (IDO) for the Tokyo-Nagoya region and one to Daini Denden Inc. for the rest of the country. NTT was therefore the only firm with a nation-wide license.

In the U.S. the market structure was debated at length, complicated by the fact that it coincides with the proceedings that eventually led to the break-up to the Bell system. Initially the FCC wanted to give only one cellular license per area, but the existing mobile radio companies won the court case against a monopoly licensing scheme in 1977. Hence, the U.S. became the first to adopt a duopoly market structure. Critics of this approach, such Calhoun (1988), claimed that the AMPS cellular standard adopted was unsuited for competition due to its limited capacity. Nevertheless, according to the ITC (1993), competition in the US has led 
to lower prices: in 1991 the average annual cost of cellular service (including the phone set) was $\$ 1500$, whereas in Japan (regional duopolies with) it was $\$ 4000$, in UK $\$ 2000$ and Germany $\$ 5700$.

Experiences in individual countries during the digital phase

In the E.U., the switch to the digital technology was seen as an opportunity to establish a uniform policy in line with the construction of the Single Market. The first step was the establishment of GSM as a common technological standard, as discussed before. The second step concerned licensing. A Directive established that for GSM services supplied in the 900 $\mathrm{MHz}$ frequency band there should be at least two firms in the market. The government was not obliged to issue the frequency licenses simultaneously, but the selection criteria should be fair and non-discriminatory. All possible combinations of licensing timing (simultaneous or sequential entry) and licensing pricing (with or without a license fee) could be observed (see Gruber and Verboven, 1999). In all E.U. countries the incumbent who already ran the analogue network obtained one license. The second license was allocated through a tender procedure ("beauty contest"), with the price offered for the license often being the overriding criterion of allocation. To preserve fair competition, the incumbent had to match the price paid, or provide some other compensatory scheme. A further provision in the Directive instructed member states to issue licenses for GSM services also in the $1800 \mathrm{MHz}$ frequency band and granting one to at least one new entrant. There are thus at least three firms supplying digital cellular services in each country.

Most Central and Eastern European countries adopted a similar licensing approach as in the E.U., establishing duopolies for GSM 900 services. The supply of GSM 1800 services

indeed tend to be persistently more asymmetric under sequential than under simultaneous entry. 
experienced some delay for two reasons: first, frequencies still had to be vacated; second, capacity shortages were not an issue because the market was growing at a lower speed than in Western Europe, and hence allocating further frequencies for cellular use was not a priority.

In Japan, four digital service licenses were granted for each region. NTT, along with two market entrants, Tu Ka Cellular Phone Company and the Digital Phone Group received national licenses. Further, IDO and DDI will be licensed to offer digital services, but only their current respective regions.

In the U.S. no particular policies were promoted. Existing cellular service firms were allowed to migrate toward digital systems on a voluntary basis. Thus the move to digital system occurred on the basis of need. This technological neutrality was supposed permit firms to respond to changes in the marketplace and to determine the rate at which new technology should be adopted. In 1995 further licenses were issued by auctions with the belief that the license would be taken by the firm who values spectrum most (see Crampton, 1995). The auctions put very little restrictions on the use of the licenses. In particular there was no specification on the technology to be adopted, nor on the type of service to be provided. The result was a relatively large number of analogue and digital firms in every area (typically 4$5)$.

\section{The econometric model of diffusion}

Technological innovations, such as mobile telecommunications, are typically not immediately adopted by all potential consumers. Consumers are heterogeneous in their preferred timing of adoption, so that a gradual diffusion of innovations may be expected. Various alternative diffusion models have been used to describe this process. Griliches 
(1957) proposed an "epidemic" diffusion model to study the diffusion of hybrid corn. ${ }^{14}$ In this model, as in other diffusion models, the flow of new adopters of the technology is related to the stock of existing adopters. When the stock of existing adopters is small, there is little risk of "contagion". As the stock increases, the risk of contagion increases, implying an exponential rise in the flow of new adopters. As the stock comes closer to the total number of potential adopters, the flow of new adopters gradually decreases and eventually becomes zero. The diffusion of the new technology thus follows an S-shaped function.

\subsection{A logistic model of diffusion}

Let $y_{i t}$ denote the number of agents that have adopted the new technology in country $i$ at time $\mathrm{t}$; let $\mathrm{yit}^{*}$ denote the total number of potential adopters. The fraction of the total number of potential adopters in country $i$ that have adopted before time $t$ is specified by the logistic distribution function:

$$
\frac{y_{i t}}{y_{i t}^{*}}=\frac{1}{1+\exp \left(-a_{i t}-b_{i t} t\right)} \text {. }
$$

The variable ait in (1) is a location or "timing" variable. It shifts the diffusion function forwards or backwards, without affecting the shape of the function otherwise. For example, when ait is very high, we may say that country $i$ at time $t$ is very "advanced" in its adoption rate. The variable $b_{i t}$ is a measure of the diffusion growth. This can be verified from differentiating (1) with respect to $t$, and rearranging:

\footnotetext{
${ }^{14}$ Chow (1967) applied such a model to study the diffusion of computers. An alternative model has been proposed by Bass (1969). For a survey, see Geroski (1998).
} 


$$
\frac{d y_{i t}}{d t} \frac{1}{y_{i t}}=b_{i t} \frac{y_{i t}^{*}-y_{i t}}{y_{i t}^{*}}
$$

This implies that $b_{i t}$ equals the growth rate in the number of adopters at time $t$, relative to the fraction of adopters that have not yet adopted at time t. Equivalently, this says that the number of new adopters at time $t$, relative to the fraction of adopters that have not yet adopted at time $t$, is a linear function of the total number of consumers that have already adopted at time t. This reflects the epidemic character of the logistic diffusion model.

It can be verified that the second derivative of (1) is positive for $y_{i t} / y_{i t} *<1 / 2$, and negative if the reverse holds. The diffusion of the number adopters thus follows an S-shaped pattern, with a maximum diffusion speed reached when half of the total number of potential adopters has effectively adopted the new technology.

In our econometric analysis we transform equation (1) as follows:

$$
\log \left(\frac{y_{i t}}{y_{i t}^{*}-y_{i t}}\right) \equiv z_{i t}=a_{i t}+b_{i t} t .
$$

The dependent variable, $\mathrm{zit}$, is the logarithm of total number of adopters relative to the number of potential adopters that have not yet adopted. Equation (2) shows that this measure for the level of adoption evolves linearly through time. Three essential elements determine the diffusion of mobile telecommunication services: the total number of potential adopters, yit* (entering in $\mathrm{zit}_{\mathrm{it}}$ ); the location variable, ait; and the growth variable bit. We specify these elements in turn. 
The total number of potential adopters, $y_{i t}{ }^{*}$.

It seems reasonable to assume that $\mathrm{yit}^{*}$ evolves proportionally to the total population, POPit. For example, one may specify:

$$
y_{i t}^{*}=\gamma_{i} P O P_{i t} \text {, }
$$

where $\gamma_{i}$ is the proportion of the population in country $i$ that eventually will adopt a mobile phone. In principle, the parameter $\gamma_{i}$ can be estimated as fixed effects for each country. In practice, it is difficult to estimate these fixed effects, since most countries are still at the early stages of diffusion. Gruber and Verboven (1998) resolved this problem by pooling the data, and estimating a parameter $\gamma$, common for all countries. This facilitates estimation because one can exploit information from both countries in early and in more mature stages of diffusion. This approach may be justified in their study, which considered the relatively homogeneous group of E.U. countries. In our present study, which covers a heterogeneous set of almost all countries in the world, this approach is harder to justify. A more flexible approach would be to allow the parameter $\gamma$ to differ across certain groups of countries, according to various economic and social determinants, such as income, the level of education or urbanisation. In practice, this approach proved difficult, in part because within each group only few countries had reached more mature stages of diffusion. ${ }^{15}$

\footnotetext{
${ }^{15}$ The problems were of two types. First, convergence was often difficult to obtain, since the model is nonlinear and the parameter $\gamma$ often causes the term within the logarithm to become negative. Second, if convergence was reached, the standard errors were quite high, essentially saying the data are at present uninformative about the total market potential.
} 
An alternative approach is followed by Dekimpe, Parker and Sarvary (1998). Instead of estimating the total number of potential adopters, they treat it as a "known" parameter. More specifically, based on industry interviews, they specify the total number of potential adopters as: "the percentage of the literate people living in urban areas having a sufficient income to afford basic telephone service". Our approach is in a similar spirit: we treat the fractions $\gamma_{i}$ as known parameters, dependent on urbanisation and economic development. Since understanding the market potential is not our main focus in this paper, our main concern was to check the robustness of the findings with respect to alternative assumptions.

The location and growth variables $a_{i t}$ and $b_{i t}$.

The location variable ait and the growth variable $b_{i t}$ in (2) can be specified in a general form as follows:

$$
\begin{aligned}
& a_{i t}=\alpha_{i}^{0}+\sum_{j=1}^{J} \alpha^{j} D_{i t}^{j}+x_{i t} \alpha \\
& b_{i t}=\beta_{i}^{0}+\sum_{j=1}^{J} \beta^{j} D_{i t}^{j}+x_{i t} \beta .
\end{aligned}
$$

The parameters $\alpha_{i}^{0}$ and $\beta_{i}^{0}$ are country-specific location and growth effects. The variables $D_{i t}^{j}$ are dummy variables to capture the effect of certain events $\mathrm{j}$. More specifically, let $T_{i}^{j}$ denote the time of a certain event $j$ in country $i$, for example the time at which a first GSM operator was introduced in country i. The dummy variable $D_{i t}^{j}$ then equals zero for $t<T_{i}^{j}$, and equals one for $t \geq T_{i}^{j}$. The parameters $\alpha^{j}$ and $\beta^{j}$ measure the effect of event $\mathrm{j}$ on the 
timing and growth variables; they are assumed to be the same across countries. The vector $x_{i t}$ includes continuous variables affecting the location or growth variables, e.g. per capita income.

Specification (4) allows an event $\mathrm{j}$ to have an effect on both the location and growth variable in an unrestricted way. Most of the empirical literature implicitly imposes structure on the specification by allowing the variable to enter only in the location or in the speed variable. We instead propose to impose some more systematic structure by assuming that there is no discontinuous change in the number of adopters after event $\mathrm{j}$ takes place. Event $\mathrm{j}$ may thus smoothly accelerate or decelerate the diffusion of innovation. More formally, the adoption level at the time of introduction of event $\mathrm{j}$, i.e. at $T_{i}^{j}$, is equal to the adoption level slightly before the time of introduction of event j, i.e. at $T_{i}^{j}-\varepsilon$ (with $\varepsilon$ small). Since at $T_{i}^{j}, D_{i t}^{j}=1$, and at $T_{i}^{j}-\varepsilon, D_{i t}^{j}=0$, this condition implies that:

$$
\begin{gathered}
\alpha_{i}^{0}+\alpha^{j}+\sum_{k \neq j} \alpha^{k} D_{i t}^{k}+x_{i t} \alpha+\left(\beta_{i}^{0}+\beta^{j}+\sum_{k \neq j} \beta^{k} D_{i t}^{k}+x_{i t} \beta\right) T_{i}^{j} \\
=\quad \alpha_{i}^{0}+\sum_{k \neq j} \alpha^{k} D_{i t}^{k}+x_{i t} \alpha+\left(\beta_{i}^{0}+\sum_{k \neq j} \beta^{k} D_{i t}^{k}+x_{i t} \beta\right) T_{i}^{j},
\end{gathered}
$$

which simplifies to:

$$
\alpha^{j}=-\beta^{j} T_{i}^{j}
$$


Substituting (4), using restriction (5), into the transformed diffusion equation (2), we obtain:

$$
z_{i t}=\alpha_{i}^{0}+x_{i t} \alpha+\left(\beta_{i}^{0}+x_{i t} \beta\right) t+\sum_{j=1}^{J} \beta^{j} D_{i t}^{j}\left(t-T_{i}^{j}\right)
$$

Note that we failed to reject the restricted equation (6) against the more general equation without restriction (5) imposed. ${ }^{16}$ We therefore focus attention on equation (6) as our econometric model of the diffusion.

\subsection{Empirical specification}

We now discuss how we include the variables referring to technology and competition in our econometric model of diffusion. First, we explain how we address the role of the timing of first entry licences. Next we explain how we consider the effects of competition, technological systems, competition between technological systems, and country characteristics.

The timing of first entry licences.

Equation (6) was first estimated without imposing any structure on the country-specific location and growth fixed effects $\alpha_{i}^{0}$ and $\beta_{i}^{0}$. An interesting hypothesis is whether there is a relationship between these country-specific effects. For example, it is possible that an "advanced" country (high location effect) experiences a lower growth rate than a country that is lagging behind (low location effect). To the extent that this is the case, there is catching-up

\footnotetext{
${ }^{16}$ To test this we estimated (6) after including $\alpha^{\mathrm{k}}$ as in the inrestricted equation. It turned out that the $\mathrm{t}$-statistics for $\alpha^{\mathrm{k}}$ where insignificant.
} 
by latecomers, or international convergence. This may occur for several reasons, such as declining investment costs through calendar time, international learning spillovers, etc... One simple way to incorporate a catching-up effect is by imposing the following relationship between $\alpha_{i}^{0}$ and $\beta_{i}^{0}$ :

$$
\beta_{i}^{0}=\beta^{0}-\lambda \alpha_{i}^{0}
$$

If late-coming countries catch up, then the parameter $\lambda$ is positive. Substituting this expression into (6), it can be verified that all countries converge to the same number of adopters (holding all other variables constant) at time $t=1 / \lambda$. Hence, the inverse of the parameter $\lambda$ may be interpreted as the time at which countries converge. This specification for a catching-up effect was imposed by Gruber and Verboven (1998). Note that this restriction may be overly restrictive in this study covering a more heterogeneous group of countries: if countries converge at all, they presumably do not converge at the same time.

We therefore also considered a more flexible way to take into account the fact that late coming countries may catch-up, to a partial extent, with early countries. In particular, we considered a specification in which countries converge at time $t=1 / \lambda$ for only a fraction $\sigma$ of the difference in initial adoption levels. At the time of introduction, $t=T_{i}^{0}$, country $\mathrm{i}$ realises an initial adoption level $z_{i T_{i}^{0}}=\alpha_{i}^{0}+\beta_{i}^{0} T_{i}^{0}$. A generalisation of (7) is:

$$
\beta_{i}^{0}=\beta^{0}-\lambda\left(\alpha_{i}^{0}-\sigma\left(\alpha_{i}^{0}+\beta_{i}^{0} T_{i}^{0}\right)\right)
$$


Substituting this expression into (6), it can be verified that at $t=1 / \lambda$ countries converge to the same adoption level up to a fraction $\sigma$ of the initial diffusion level $\alpha_{i}^{0}+\beta_{i}^{0} T_{i}^{0}$. For example, if $\sigma=0$, then convergence is as under (7); in contrast, if $\sigma=1$, then there is convergence at $t=1 / \lambda$, except for any possible differences in adoption levels at the time of introduction. Note that (8) still implies, independent of $\sigma$, that two countries $i$ and $j$, which start adopting at a different time, converge to the same adoption level at $t=1 / \lambda$, provided they are equally "advanced" (i.e. $\alpha_{i}^{0}=\alpha_{j}^{0}$ ). Yet (8) is distinct from (7) whenever two countries $\mathrm{i}$ and $\mathrm{j}$ are not equally advanced. An example is given in Figure 5, plotting the (transformed) diffusion curve for three countries when $\sigma=1$. Country 1 and 2 start adoption at a different date but at the same level. They converge at $t=1 / \lambda$. Country 1 and 3 start adoption at a different data and also at different levels? They converge at time $t=1 / \lambda$, up to the initially different level. Countries 2 and 3, which start at the same date but a different level, do not converge.

The timing of additional entry licenses.

The effects of additional entry licenses are taken into account through several dummy variables $D_{i t}^{j}$. We make a distinction between introducing competition among analogue operators, and introducing competition between digital operators. Furthermore, we distinguish between simultaneous entry, where two or more operators enter at once, and sequential entry, where one operator enjoys a monopoly period before additional entrants enter. Finally, we distinguish between an initial effect of competition on diffusion growth, and the effect after one year. The reasons for including all these variables have been discussed in the previous section. We now define the various dummy variables more precisely. 
- COMP_A: dummy variable equal to 1 as soon as competition between analogue operators is introduced.

- COMP_D: dummy variable equal to 1 as soon as competition between digital operators is introduced.

- COMP_A,SM: dummy variable equal to 1 as soon as simultaneous competition between analogue operators is introduced.

- COMP_D,SM: dummy variable equal to 1 as soon as simultaneous competition between digital operators is introduced.

- COMP_A,SQ: dummy variable equal to 1 as soon as sequential competition between analogue operators is introduced.

- COMP_D,SQ: dummy variable equal to 1 as soon as sequential competition between digital operators is introduced.

The simultaneous and sequential competition variables are of course mutually exclusive: if COMP_A,SM=1, then COMP_A,SQ=0 and vice versa; and if COMP_D,SM=1, then COMP_D,SQ $=0$ and vice versa. In contrast, the analogue and digital competition variables are not mutually exclusive. It is thus possible to have competition between both analogue and digital operators, but also to have competition in one technology but not in the other.

For the sequential competition variables, we also considered one-period lags: COMP_A,SQ(1), and COMP_D,SQ(-1). These lagged variables measure the effect on the growth of adoption in the year prior to competition.

Technological systems and competition between technological systems. 
We introduce dummy variables to measure the effect of different technological systems. We consider first a set of dummy variables to identify the effect of alternative technologies when these are introduced as a single analogue or digital standard:

- NMT: dummy variable equal to 1 , if NMT is the single analogue standard

- TACS: dummy variable equal to 1, if TACS is the single analogue standard

- AMPS: dummy variable equal to 1, if AMPS is the single analogue standard

- C450: dummy variable equal to 1 , if C450 is the single analogue standard

- GSM: dummy variable equal to 1, if GSM is the single digital standard

- NONGSM: dummy variable equal to 1 , if a non-GSM technology is the single digital standard.

In addition to these single standard variables, we introduce variables to measure the effect on the diffusion when different technological systems compete with each other. In principle, one could introduce dummy variables for each pair (or triple) of competing analogue or digital system. However, there are typically only few observations corresponding to each such pair, as was shown in the previous section. For this reason, we use the following summary measures.

- COMPSYS_A: dummy variable equal to 1 , if there are two or more competing analogue systems

- COMPSYS_D: dummy variable equal to 1 , if there are two or more competing digital systems.

To capture possible effects on the diffusion of innovation when a digital system is introduced without a previously introduced and co-existing analogue system we introduce the following variable: 
- SINGLE_D: dummy variable equal to 1, if a digital system is introduced without a previously introduced and co-existing analogue system.

\section{Country characteristics.}

We include the following variables in the vector $x_{i t}$, referring to country characteristics affecting the timing and speed of innovation.

- GDPCAP: income per head, measured as real gross domestic product per capita converted into U.S. dollars. This variable is expected to have a positive impact on the diffusion of innovation.

- MAINCAP: the number of fixed mainlines per capita. This variable captures the size of the fixed network and may have a positive or a negative effect, depending on whether adopters view mobile telecommunications services as a complement of a substitute for a fixed connection.

- WAITLIST: the ratio between registered applications for a fixed line and the number of connected fixed line subscribers. This variable thus measures the waiting list for a fixed line connection, and captures the level of efficiency of the fixed operator, as well as the current "excess demand" for telecommunication services. It is expected to have a positive impact on the diffusion.

\subsection{Data description}

The study is based on annual data and covers 140 countries that have adopted cellular telecommunications. Apart from the countries that have not adopted cellular telecommunications, this sample excludes 22 mostly very small countries. In total, the sample represents $94 \%$ of the world's population. The time series starts in 1981 and therefore 
covers all cellular markets from the first year, with the exception of Japan where this was introduced in 1979. The data on the number of analogue and digital subscribers, the waiting list and the number of fixed mainlines is from the World Telecommunications Indicators of the ITU (1999). The information about the type of system is gathered from various sources, such as the trade press (Mobile Communications and EMC), GSM Memorandum of Understanding (http: $\mid \underline{w w w . g s m w o r l d . c o m)}$, Beckers and Smits (1997) and Garrard (1998). The macroeconomic data such as GDP and population are taken from the World Bank's World Development Indicators.

\section{Empirical Results}

After adding an error term, we estimate the diffusion model (6) using (non-linear) least squares. We first estimated (6) without imposing any restrictions on the country-specific location and growth fixed effects. While this produced a good fit of the data $\left(\mathrm{R}^{2}=.98\right)$, the standard errors of most coefficients were relatively high. To obtain a better understanding of the fixed effects, we plotted the growth effects against the location effects, as drawn on Figure 6. This Figure indicates a strong negative relationship: advanced countries (with a high location effect) have a strong tendency to grow slower than countries that are lagging behind (with a low location effect). This negative relationship was our motivation for estimating the model under restrictions (7) or (8), testing for the presence of a catching-up effect, or international convergence.

Before presenting our estimates, note that we considered the robustness of our empirical results with respect to various specifications: (i) impose restriction (7) or its generalisation (8); (ii) include or exclude country characteristics variables; (iii) restrict the market potential 
to the same proportion for all countries, or allow the proportion to vary across countries. ${ }^{17}$ The empirical results essentially remained robust with respect to changes in any of these dimensions. Table 4 presents the estimates for various alternative specifications.

The first column shows estimates of the most restricted specification: no country characteristics are included; and constraint (7) is applied, i.e. $\sigma=0$, imposing countries to simultaneously converge to the same diffusion levels at $t=1 / \lambda$. The second column shows estimates when country characteristics, GDPCAP, MAINCAP and WAITLIST are also included. The third column allows $\lambda$ to vary across groups of countries. The fourth column generalises (7) to the more flexible constraint (8).

\section{The effect of country characteristics}

Fixed country effects enter the location and growth parameters after imposing the restrictions (7) or (8). This still allows us to estimate the effect of country characteristics on the location and growth effects. This is done in specifications (ii)-(iv). Countries with a high income per capita (GDPCAP) tend to be more advanced in adopting mobile phones, yet the effect is diminishing over time. The overall effect of income on mobile penetration remains positive roughly until 2008 (for specification (i)). This is intuitive, given the large fraction of the budget to be spent on a mobile phone during the early years, and the declining prices afterwards. Similarly, countries with a large fixed network (MAINCAP) tend to be more advanced in adopting mobile phones. Yet again the effect is diminishing over time and becomes negligible around 2004 (for specification (i)). This suggests that the fixed network

\footnotetext{
${ }^{17}$ In some restricted specifications, we could estimate the proportion $\gamma$ and found values roughly ranging between .4 and .5 . We correspondingly choose a value of $\gamma=.45$ when we restrict it to be the same for all countries. We also divided the countries into four classes of economic development, according to World Bank classification. Estimates of $\gamma$ per group could not be obtained, but the results were virtually unaffected by
} 
is largely viewed as a complement to mobile phones. ${ }^{18}$ Finally, countries with a large waiting list for a fixed line connection initially have insignificantly different mobile penetration levels. Yet these countries experience a strong and significantly higher annual growth than countries with a low waiting list. This indicates that countries with a relatively inefficient fixed operator become more advanced in adopting mobile phones as time evolves. Mobile telecommunications may thus be a very suitable tool for providing telecommunications access in inefficient markets, i.e. typically developing countries.

\section{The role of technological systems and systems competition}

First, consider the effects on the diffusion growth of the various alternative technological systems when these were the single analogue or digital standard in a country. These effects may be interpreted as measuring "pure" quality differences between technological systems, since consumers cannot substitute to competing technological systems when there is a single standard. The benchmark is the "national analogue standard", which prevailed during some years in various countries.

The estimates show that some technological systems significantly affect the diffusion growth, relative to this benchmark. The analogue NMT and especially TACS technological standards significantly slow down the growth of diffusion, consistent with common wisdom on the relative inefficiency of both systems. The digital non-GSM standards significantly accelerate the growth of diffusion in most specifications. The effect of the digital GSM standard is only modest and usually insignificant. This latter finding contrasts with common wisdom and European policy reports on the successes of the GSM standard.

changing parameter values (e.g. by setting $\gamma$ equal to .35 for the least developed group, $\gamma=.45$ for the next group and so on). 
Second, consider the effect on the diffusion growth when there were two or more competing analogue or digital standards. In principle, one may separately consider the effect of each competing pair (or triple) of technological systems. Since there are many possible pairs, most of them having only few observations, we summarise the effects in two variables, one measuring the effect on the diffusion growth when two or more analogue systems compete (COMPSYS_A) and one measuring the effect when two digital technologies compete (COMPSYS_D).

All specifications show that competition between analogue technological systems significantly slowed down the growth in mobile diffusion, by a factor of about 5-15 percent. This finding is consistent with the hypothesis that setting a standard makes consumers more eager to adopt a new technology in the presence of network effects. In contrast, the presence of competition between digital technological systems did not significantly affect the growth in mobile diffusion. The latter finding contrasts with some common wisdom that installing the single digital GSM standard in Europe has been responsible for the high mobile penetration levels.

How can the different effects of competing systems for the analogue and the digital technology be reconciled? Recall that there are both advantages and disadvantages from having competing systems rather than single standards. The major advantage of allowing competing systems is that markets may not be locked in into inferior technologies and that firms are motivated to continuously invest in $R \& D$ to improve the quality of their technology. Major disadvantages of allowing competing systems are that network externalities are more limited (especially when roaming is valued highly) and that economies of scale in the manufacture of equipment are not fully exploited. Our empirical results then

\footnotetext{
${ }^{18}$ For a more detailed analysis of the role of the fixed network on mobile diffusion see Cadima and Barros (1998).
} 
indicate that the disadvantages of allowing competing systems were dominant during the analogue area, and were balanced by the advantages during the digital area. This confirms the analysis on digital systems competition advanced by Shapiro and Varian (1999), who argue that the decentralised approach followed in the U.S. gave the innovative but controversial CDMA technology (in terms of capacity advantages) a chance to develop. In Europe, consumers have been locked in into the comparatively less efficient GSM standard.

Finally, we considered the effect on the diffusion growth when the digital technology was introduced without a preceding analogue period. For all specifications, we find an insignificant effect. The diffusion of digital mobile services thus grew equally fast in countries with a non-predominant second-generation standard as in other countries. This suggests the absence of lock-in effect into a less efficient (analogue) system.

\section{The timing of first entry licenses}

Let us now consider the role of the timing of first entry licences. As Figure 4 showed, there is a strong negative relationship between the growth and the location effects of each country. Columns (i) and (ii), which impose restriction (7), find a precise estimate of $\lambda$ of .026 and .024 , respectively. This implies that countries that are less advanced in the level of adoption catch up by growing faster than early countries. Nevertheless we find that the catching-up is rather slow: the date of convergence in adoption levels $(t=1 / \lambda)$ is $\mathrm{t}=38.6$ and $\mathrm{t}=42.1$, in the specifications under column (i) and (ii), respectively. ${ }^{19}$ Because $t=0$ corresponds to the year 1980, this means that countries would converge in 2019 and 2022, respectively. The estimated convergence dates are later than in Gruber and Verboven (1998), who found

\footnotetext{
${ }^{19}$ The corresponding standard errors of the convergence time are 2.1 and 5.1 respectively.
} 
convergence around 2008. This is not surprising given that the set of countries we consider here is much more heterogeneous than the set of E.U. countries.

To incorporate the fact that countries may in fact be heterogeneous, we relaxed restriction (7) in two ways. First, we allowed $\lambda$ to vary across the following four groups of level of economic development (according to the World Bank classification): low, lower-middle, upper-middle and high income countries. The estimate in column (iii) shows that there are indeed significant differences in catching-up across the four groups of countries. Countries from group 1 and group 2 (least developed countries) show the slowest convergence (around year 2017), preceded by countries from group 3 (around 2011) and 4 (around 2008). Even though column (iii) thus reveals a faster catching-up by late-coming countries if they come from more developed countries (group 3 and group 4), we find the delay still quite substantial.

Second, we estimated the model using the more flexible constraint (8). This constraint does not impose countries to converge to the same adoption levels $(\sigma=0)$, but instead allows for the possibility of convergence up to a positive fraction $(\sigma>0)$ of the initial adoption lag or lead. The results in column (iv) now show an estimate of $\lambda$ equal to 0.044 and an estimate of $\sigma$ equal to .85 , which is in fact not significantly different from 1 . These results imply that countries converge around the year 2003, but only up to the initial adoption lag or lead at the time of the first entry licence $t=T_{i}^{0}$. For example, two hypothetical countries that issue a first licence at the same time but with different initial adoption levels would not converge. In contrast, two hypothetical countries that issue a first licence at different points in time but experience the same initial level fully converge. These results further illustrate the importance of the timing of issuing first licences in the growth of diffusion. While countries that issued first licenses at a rather late date, do experience a catching-up effect, convergence 
is delayed rather significantly. Welfare costs due to delays in issuing licences to cellular telecommunications can be very high. Hausman (1998) estimated that the regulatory delay in providing analogue cellular licenses cost the US economy 100 billion US\$.

\section{The introduction and timing of additional entry licenses}

All specifications in Table 4 consider the effects of introducing two or more competing operators during the analogue and during the digital area. All specifications show that introducing competition between operators had a significant impact on the growth of mobile diffusion. The effect was especially large during the digital area, and less pronounced during the analogue area. This is consistent with our hypothesis that capacity plays a major role in explaining the magnitude of the competition effects. During the analogue area capacity was constrained, thereby mitigating any positive effects from competition. Casual evidence suggests that prices during the analogue area indeed remained high even when there was competition.

We next explored in further detail the effects of competition, by distinguishing between two types of competition: simultaneous entry and sequential entry. We furthermore considered the possibility of pre-emptive behavior by the incumbent firm, in the case of sequential entry. The results are shown on Table $5 .^{20}$ In the first column we compare simultaneous entry with sequential entry. The specification differs from the ones in Table 4, in that the competition variables are now interacted with a dummy variable identifying whether it concerns simultaneous or sequential entry. It can be seen that the impact on the diffusion of mobile adoption was significantly stronger when entry was introduced sequentially than when it was introduced simultaneously. This finding is consistent with our hypothesis on the effects of 
entry when consumers have switching costs, as outlined in section 3 . Under simultaneous entry, firms maintain more or less symmetric market shares (as confirmed by the evidence offered by Gruber, 1999). This gives them incentives to compete more softly. In contrast, under sequential entry the second entrant starts from a low market share and needs to compete vigorously to obtain part of the incumbent's installed base, which induces further aggressive responses by the incumbent. Notice that the sequential entry effect is especially strong during the digital area when capacity (for both the incumbent and the entrant) is large, but it is also present during the more capacity constrained analogue area.

In the second column of Table 5 we investigate whether, in the case of sequential entry, incumbents have an incentive to pre-empt entry in the period prior to actual entry. This may be done, for example, by charging low prices or following aggressive marketing campaigns. To address this question, we included a lagged dummy variable for the sequential entry variables. It can be seen that this lagged variable is significant and large during both the analogue and the digital area. Note that during the digital area the growth in mobile penetration arising from competition remains roughly equally strong after the pre-emptive actions by the incumbent (.350-.002), whereas during the analogue area most growth arising from competition is actually realized during the pre-emptive period prior to actual entry (growth effect after pre-emptive period of .471-.408).

\section{Conclusions}

This paper has studied the evolution of the cellular mobile telecommunications services industry. One can distinguish between an analogue phase, during which the industry was potentially capacity constrained, and a digital phase, during which capacity expanded

\footnotetext{
${ }^{20}$ The results include the same variables as in specificiation (i) of Table 4 . The results were robust for all other specifications we considered.
} 
considerably. The evolution of the industry is particularly interesting because of the central role played government policies, such as entry regulation and technology standards. These policies affected the evolution of the industry in a different way during both phases. A unique panel data set is used covering the entire evolution of the industry from 1981-1997 for almost all countries in the world. The first part of the paper (up to section 3 ) describes the relevant technological characteristics and the various government policies. The second part of the paper uses a logistic diffusion model to ask how government policies have affected the evolution of the industry. With respect to country characteristics we find that income per capita, the size of the fixed network and the waiting list for the fixed network all have a positive effect on the level of diffusion. Our main results relating to the effects of government intervention on the evolution of the industry can be summarized in various points.

First, the actual timing at which first entry licenses are issued has a significant impact on the diffusion of mobile services. It is found that countries that issue first licenses at later dates converge to early moving countries, though at a relatively slow pace, potentially creating large consumer losses.

Second, the introduction of second licenses (competition) has a significant impact on the diffusion of mobile services. The effect is especially strong during the digital phase. This is consistent with the existence of binding capacity constraints during the analogue phase, compared to a drastically expanded capacity in the digital phase.

Third, the timing at which second licenses are introduced turns out to be relevant. Simultaneous entry has a modest (but significant) impact on the diffusion of mobile services, whereas sequential entry has a strong impact, especially during the digital phase. There is also evidence of pre-emptive behavior by the incumbent (in case of sequential entry). These 
findings can be explained by strategic behavior by the operators in the presence of consumer switching costs.

Finally, setting technology standards rather than allowing multiple competing systems turns out to be a relevant determinant of the evolution of the industry, at least during the analogue phase. We find that analogue standard help to develop the market faster compared to competing analogue systems. This is consistent with the presence of network effects. Imposing a digital standard (e.g. the GSM in the E.U.) does not seem to significantly affect the diffusion. This suggests that during the digital phase the advantages from competing systems (e.g. the emergence of the new CDMA system) roughly compensate for the advantages from a single standard. We also compared countries that immediately adopted a digital system with countries that first adopted an analogue system. It turns out that the diffusion of digital mobile services grew equally fast in both types of countries. A nonpredominant second-generation standard thus does not significantly speed up diffusion, suggesting no lock-in effect into a less efficient (analogue) system.

Our analysis on the effects of government policies on the evolution of an industry was made possible by the large differences in policies across countries and the significant changes in polies over time. The lack of consensus regarding the policy options that were taken may be the consequence of different objectives or different structural conditions in different countries. Of course, since our study concerns an emerging industry subject to rapid technological changes and other uncertainties, the heterogeneity of policies across countries may also be the result of mistakes. A more detailed analysis into understanding the policies followed by the various countries would be an interesting topic for further research. In the mean time, we hope that our empirical analysis can provide lessons to policy makers to improve decision making relating to entry and standards regulation in the cellular mobile industry and elsewhere. 


\section{References}

Ahn,H. and Lee, M. An Econometric Analysis of the Demand for Access to Mobile Telephone Networks. Information Economics and Policy, 11, 1999, 297-305.

Appleby, M.S. The UK Cellular System. In Macario, R.C.V. Personal \& Mobile Radio Systems. London, Peter Peregrinus, 1991.

Bass, F.M. A New Product Model for Consumer Durables. Management Science, 15, 1969, 215-227.

Bekkers,R. and Smits;J. Mobile telecommunications: Standards, Regulation and Appliations. Norwood, Artech House, 1997.

Cadima, N. and P. Pita Barros, 1998, The impact of mobile phone diffusion on the fixed link network, mimeo.

Chow, G. 1967 Technological Change and the Demand for Computers. American Economic Review, 57, 1117-1130.

Cramton,P.C. Money out of Thin Air. The Nationwide Narrowband PCS Auction. Journal of Economics and Management Strategy, 1995, 4, 267-343.

Garg,V.K. and J.E.Wilkes, Wireless and Personal Communications Systems, Upper Saddle River, HJ, Prentice Hall, 1996.

De Kimpe, M. G., P.M. Parker and M. Sarvary, Staged Estimation of International Diffusion Models: An Application to Global Cellular Telephone Adoption, Technological Forecasting and Social Change, 1998, 57, 105-132.

Garrard, G.A. Cellular Communications: Worldwide Market Developments. Norwood, Artech House, 1998. 
Genty,L. Auctions and Comparative Hearings: Two Ways to Attribute Spectrum Licenses. Communications and Strategies, 35, 1999, 11-43.

Geroski, P., Models of Technology Diffusion, C.E.P.R. Discussion Paper no.2146, 1999.

Griliches,Z. (1957) "Hybrid Corn: An Exploration in the Economics of Technical Change." Econometrica, 25, 501-522.

Gruber, H., An investment view of mobile telecommunications in the European Union, Telecommunications Policy, 23, 1999, 521-538.

Gruber, H. and Hoenicke M. The Road Toward Third Generation Mobile Telecommunications. Info, 1,3, 1999, 213-224.

Gruber, H. and Verboven, F., The Diffusion of Mobile Telecommunications Services in the European Union, CEPR Discussion paper No.2054, 1999.

Guerci, C.M., Monopolio e concorrenza nelle telecomunicazioni. Il caso Omnitel. Milan, Il Sole 24 Ore, 1998.

Hausman, J.A., Valuing the Effect of Regulation on New Services in Telecommunications. Brooking Papers on Economic Activity. Microeconomics. 1997.

ITC, Global Competitiveness of U.S. Advanced-Technology Industries: Cellular Communications. Publication 2646. Washington, U.S, International Trade Commission, 1993.

ITU, World Telecommunication Development Report 1999. Mobile Cellular. Geneva, International Telecommunications Union, 1999.

Jha R. and Majumdar, S. A Matter of Connections: OECD Telecommunications Sector Productivity and the Role of Cellular technology diffusion. Information Economics and Policy, 11, 1999, 243-269. 
Jung, V. and Warnecke, H.-J. Handbuch für die Telekommunikation. Berlin, Springer, 1998. Kargman,H. Land Mobile Communications: The Historical Roots. In R.Bowers; A.M. Lee and C.Hershey (eds.) Communications for a Mobile Society. Beverly Hills, Sage Publications, 1978.

Katz, M.L. and Shapiro,C. Systems Competition and Network Effects. Journal of Economic Perspectives, 8,2, 1994, 93-115.

Klemperer, P., Price Wars Caused by Switching Costs, Review of Economic Studies, 56, $1989,405-420$.

Laffont, J.-J. and J. Tirole, Competition in Telecommunications, forthcoming.

Levin, H.J. The Invisible Resource. Use and Regulation of the Radio Spectrum. Baltimore, Johns Hopkins Press, 1971.

Liebowitz S.J. and Margolis, S.E. Winners, Losers \& Microsoft. Competition and Antitrust in High Technology. Oakland, The Independent Institute, 1999.

Manguian, J.P. Les Radiocommunications. Paris, Presses Universitaires Francaises, 1993.

Mölleryd, B.G. (1997) The Building of a World Industry. The Impact of Entrpreneurship on Swedish Mobile Telephony. Teldok, 28e. Stockholm.

Müller J. and Toker, S. Mobile Communications in Europe. in Steinfield, C., Bauer,J.M. and Caby,L. Telecommunications in Transition. Policies, Services and Technologies in the European Community. Thousand Oaks, Sage, 1994.

Nattermann, P.M. Estimating Firm Conduct: The German Cellular Market. Thesis Georgetown University, Washington, 1999.

Palmberg, C. Industrial Transformation Trough Public Procurement? The Case of the Finnish Telecommunications Industry. Thesis, Abo University, 1998. 
Parker,P.M. and Röller,L-H. Collusive Conduct in Duopolies: Multimarket Contact and Cross-Ownership in the Mobile Telephone Industry. RAND Journal of Economics, 1997, 28, 304-322.

Rappaport, T.S. Wireless Communications. Principles and Practice. Upper Saddle River, HJ, Prentice Hall, 1996.

Redl S.M., Weber, M.K. and Oliphant, M.W. An Introduction to GSM. Norwood, Artech House, 1995.

Saloner, Garth, and Andrea Shepard, Adoption of technologies with network effects: an empirical analysis of the adoption of automated teller machines, RAND Journal of Economics, 26, 479-501.

Shapiro, C. and Varian, H.R. Information rules. A Strategic Guide to the Network Economy. Boston, Harvard Business School Press, 1999.

Tyson, Laura D'Andrea "Who's Bashing Whom? Trade Conflict in High Technology Industries.", Institute for International Economics, Washington, 1992.

Valletti, T.M. and Cave, M. Competition in UK Mobile Communications. Telecommunications Policy, 22, 109-131, 1998.

Van de Wielle, B. and F. Verboven, 1998, Simultaneous versus sequential entry with consumer switching costs, University of Antwerp, mimeo.

Webb, W. Understanding Cellular Radio. Norwood, Artech House, 1998. 
Table 1. Characteristics of analogue cellular systems

\begin{tabular}{|l|l|l|l|l|l|l|l|}
\hline System & $\begin{array}{l}\text { Year of } \\
\text { first } \\
\text { adoption }\end{array}$ & $\begin{array}{l}\text { Country of } \\
\text { first } \\
\text { adoption }\end{array}$ & $\begin{array}{l}\text { Transmission } \\
\text { frequency } \\
\text { MHz }\end{array}$ & $\begin{array}{l}\text { Channel } \\
\text { band width } \\
k H z\end{array}$ & $\begin{array}{l}\text { Number } \\
\text { of speech } \\
\text { channel }\end{array}$ & $\begin{array}{l}\text { Channel bit } \\
\text { rate } \\
\text { Kb/s }\end{array}$ & $\begin{array}{l}\text { Spectral } \\
\text { efficiency } \\
\text { b/s/Hz }\end{array}$ \\
\hline & & & & & & & \\
\hline NTT & 1979 & Japan & $400-800$ & 25 & 1640 & 0.3 & 0.012 \\
\hline NMT-450 & 1981 & $\begin{array}{l}\text { Scandinavi } \\
\text { a }\end{array}$ & $450-470$ & 25 & 180 & 1.2 & 0.048 \\
NMT-900 & 1986 & & $890-960$ & 12.5 & 2000 & & 0.096 \\
\hline AMPS & 1983 & US & $824-845$ & 30 & 832 & 10 & 0.333 \\
\hline C-450 & 1985 & Germany & $450-465$ & 20 & 573 & 5.28 & 0.264 \\
\hline TACS & 1985 & UK & $890-960$ & 25 & 1000 & 8 & 0.320 \\
\hline RTMS* & 1985 & Italy & $450-465$ & 25 & 200 & & \\
\hline RC 2000* & 1985 & France & $200-400$ & 12.5 & 1700 & & \\
\hline SOHF: And
\end{tabular}

Source: Authors based on Garg and Wilkes (1996); ITC (1993)

* Also referred to as "quasi-cellular", because of restrictions on handover between cells.

$\mathrm{b}=$ bit, $\mathrm{s}=$ second, $\mathrm{Hz}=\mathrm{Hertz}$

$1 \mathrm{MHz}=1$ million Hertz

$1 \mathrm{kHz}=1000$ Hertz

Table 2. Characteristics of digital cellular systems

\begin{tabular}{|l|l|l|l|l|l|l|l|l|}
\hline System & $\begin{array}{l}\text { Year of } \\
\text { first } \\
\text { adoptio } \\
n\end{array}$ & $\begin{array}{l}\text { Country } \\
\text { of first } \\
\text { adoption }\end{array}$ & $\begin{array}{l}\text { Access } \\
\text { technology }\end{array}$ & $\begin{array}{l}\text { Transmission } \\
\text { frequency } \\
M H z\end{array}$ & $\begin{array}{l}\text { Channel } \\
\text { band } \\
\text { width } \\
k H Z\end{array}$ & $\begin{array}{l}\text { Number } \\
\text { of speech } \\
\text { channels }\end{array}$ & $\begin{array}{l}\text { Channel } \\
\text { bit rate } \\
\text { Kb/s }\end{array}$ & $\begin{array}{l}\text { Spectral } \\
\text { efficiency } \\
\text { b/s/Hz }\end{array}$ \\
\hline $\begin{array}{l}\text { GSM 900 } \\
\text { GSM 1800 }\end{array}$ & 1990 & $\begin{array}{l}\text { EU } \\
\text { EU }\end{array}$ & TDMA & $\begin{array}{l}890-960 \\
1710-1880\end{array}$ & 200 & $\begin{array}{l}1000 \\
1500\end{array}$ & 270.8 & 1.35 \\
\hline DAMPS & 1991 & US & TDMA & $824-894$ & 30 & 1666 & 48.6 & 1.62 \\
\hline IS-95 & 1993 & US & CDMA & $824-894$ & 1250 & & & $1.75^{*}$ \\
\hline JDC & 1993 & Japan & TDMA & $800-1500$ & 25 & 1920 & 14 & 1.68 \\
\hline
\end{tabular}

* Not strictly comparable.

Source: Author based on Garg and Wilkes (1996) and Webb (1998).

$\mathrm{b}=$ bit, $\mathrm{s}=$ second, $\mathrm{Hz}=\mathrm{Hertz}$

$1 \mathrm{MHz}=1$ million Hertz

$1 \mathrm{kHz}=1000$ Hertz 
Table 3. The policy matrix: number of countries adopting different policies for analogue/digital cellular systems (Status 1997).

\begin{tabular}{|l|l|l|l|}
\hline & $\begin{array}{l}\text { Single system } \\
\text { (Standard) }\end{array}$ & Multiple systems & Total \\
\hline Monopoly & $83 / 39$ & $5 / 0$ & $88 / 39$ \\
\hline Oligopoly & $22 / 40$ & $8 / 8$ & $30 / 48$ \\
\hline Total & $105 / 79$ & $13 / 8$ & $108 / 87$ \\
\hline
\end{tabular}

Note: First/second number refers to the countries adopting analogue/digital cellular systems.

Source: World Telecommunications Indicators, Mobile Communications and EMC; own calculations. 
Table 4. Empirical results for diffusion equation (6)

\begin{tabular}{|c|c|c|c|c|}
\hline & (i) & (ii) & (iii) & (iv) \\
\hline$\lambda$ & $.027 * *(.001)$ & $.024 * *(.003)$ & $.028 * *(.003)$ & $.043 * *(.003)$ \\
\hline$\lambda_{2}$ & & & $.0004(.0016)$ & \\
\hline$\lambda_{3}$ & & & $.0051 * *(.0016)$ & \\
\hline$\lambda_{4}$ & & & $.0086^{* *}(.0018)$ & \\
\hline$\sigma$ & & & & $.839 * *(.090)$ \\
\hline$\beta_{0}$ & $.277 * *(.031)$ & $.283 * *(.058)$ & $.186^{* *}(.051)$ & $.307 * *(.050)$ \\
\hline \multicolumn{5}{|c|}{ Growth parameters for competition variables } \\
\hline COMP_A & $.050 * *(.020)$ & $.033(.023)$ & $.033(.021)$ & $.055 *(.025)$ \\
\hline COMP_D & $.166^{* *}(.043)$ & $.152 * *(.047)$ & $.136 * *(.044)$ & $.162 * *(.046)$ \\
\hline \multicolumn{5}{|c|}{ Growth parameters for technology variables } \\
\hline NMT & $-.090 * *(.027)$ & $-.068 *(.030)$ & $-.044 *(.028)$ & $-.024(.028)$ \\
\hline TACS & $-.142 * *(.030)$ & $-.1304 * *(.036)$ & $-.084 *(.034)$ & $-.090 * *(.035)$ \\
\hline AMPS & $-.070 *(.032)$ & $-.012(.036)$ & $-.007(.035)$ & $-.034(.037)$ \\
\hline $\mathrm{C} 450$ & $-.018(.044)$ & $.031(.050)$ & $-.012(.046)$ & $.081(.053)$ \\
\hline GSM & $.015(.038)$ & $.021(.042)$ & $.056(.042)$ & $-.049(.042)$ \\
\hline NONGSM & $.137(.118)$ & $.396^{* *}(.140)$ & $.443 * *(.136)$ & $.482 * *(.137)$ \\
\hline COMPSYS_A & $-.134 * *(.038)$ & $-.106 * *(.041)$ & $-.108 * *(.042)$ & $-.054(.039)$ \\
\hline COMPSYS_D & $-.090(.157)$ & $.131(.197)$ & $.284(.197)$ & $-.055(.194)$ \\
\hline SINGLE_D & $.015(.097)$ & $.094(.104)$ & $.110(.100)$ &.$-.100(.110)$ \\
\hline \multicolumn{5}{|c|}{ Location parameters for country characteristics } \\
\hline GDPCAP & & $.107 * *(.027)$ & $.116^{* *}(.030)$ & $.071 * *(.022)$ \\
\hline MAINCAP & & $1.130 * *(.258)$ & $1.508 * *(.345)$ & $1.195^{* *}(.197)$ \\
\hline WAITLIST & & $-.276(.212)$ & $-.156(.224)$ & $-.481(.191)$ \\
\hline \multicolumn{5}{|c|}{ Growth parameters for country characteristics } \\
\hline GDPCAP & & $-.004 * *(.001)$ & $-.006^{* *}(.002)$ & $-.006(.009)$ \\
\hline MAINCAP & & $-.05 * *(.01)$ & $-.073 * *(.018)$ & $-.03629 * *(.008)$ \\
\hline WAITLIST & & $.058 * *(.013)$ & $.056 * *(.014)$ & $.072 * *(.014)$ \\
\hline
\end{tabular}

* Statistically significant at 5 percent level.

** Statistically significant at 1 percent level. 
Table 5. Competition entry effects, simultaneous versus sequential entry

\begin{tabular}{|l|l|l|}
\hline & \multicolumn{1}{|c|}{ (i) } & (ii) \\
\hline & \multicolumn{2}{|c|}{ Analogue } \\
\hline COMP_A,SM & $.012(.025)$ & $.021(.025)$ \\
\hline COMP_A,SQ(-1) & \multicolumn{2}{|c|}{$.471^{* *}(.130)$} \\
\hline COMP_A,SQ & $.108^{* *}(.025)$ & $-.408^{* *}(.146)$ \\
\hline & \multicolumn{2}{|c|}{ Digital } \\
\hline COMP_D,SM & $.122^{* *}(.044)$ & $.156^{* *}(.044)$ \\
\hline COMP_D,SQ(-1) & \multicolumn{2}{|c|}{$.350^{* *}(.129)$} \\
\hline COMP_D,SQ & $.419^{* *}(.087)$ & $-.002(.181)$ \\
\hline
\end{tabular}

* Statistically significant at 5 percent level.

** Statistically significant at 1 percent level. 
Figure 1. The diffusion of analogue cellular technologies (number of countries adopting a system)

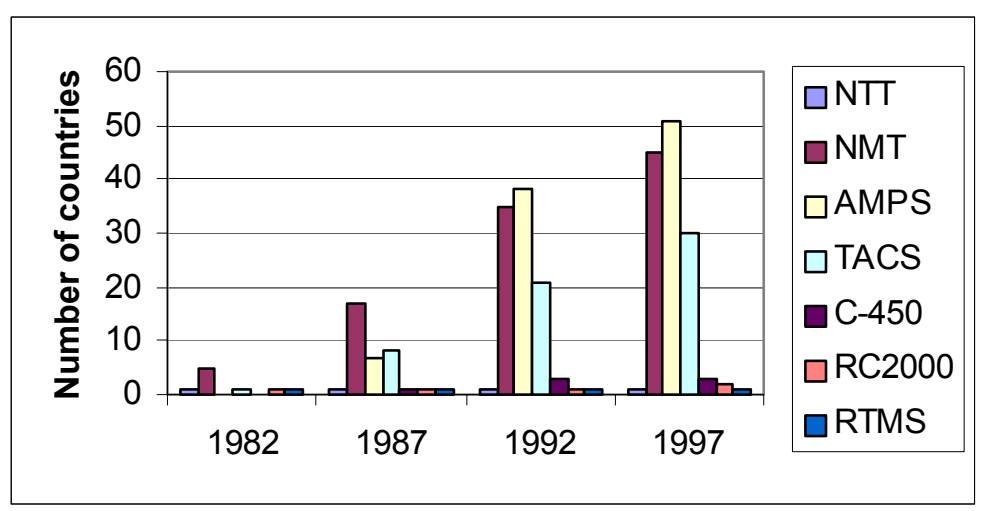

Figure 2. The diffusion of digital cellular technologies (number of countries adopting a system)

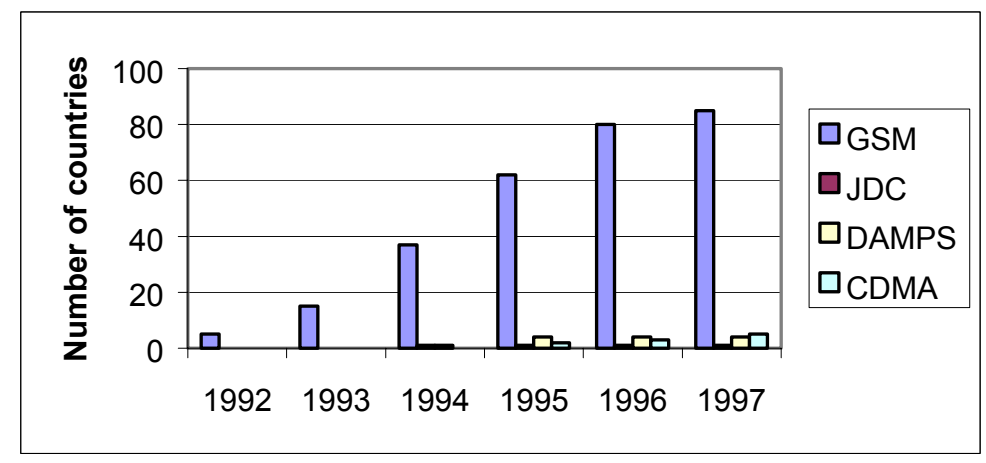


Figure 3. Fraction of countries adopting a monopoly for analogue and digital systems.

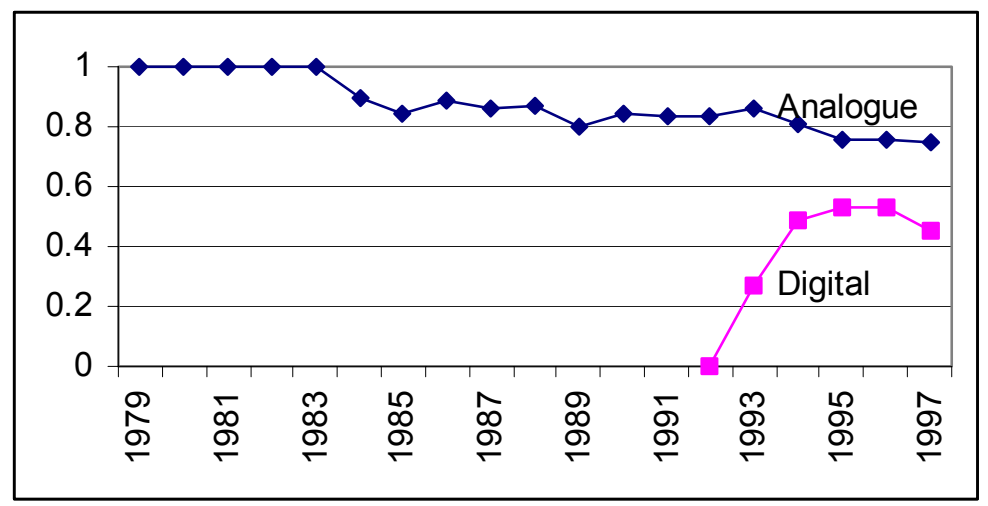

Legenda: The figure indicates the number of countries hat have a monopoly out of the total adopting countries

Figure 4. Fraction of countries adopting single system (standard) for analogue and digital systems.

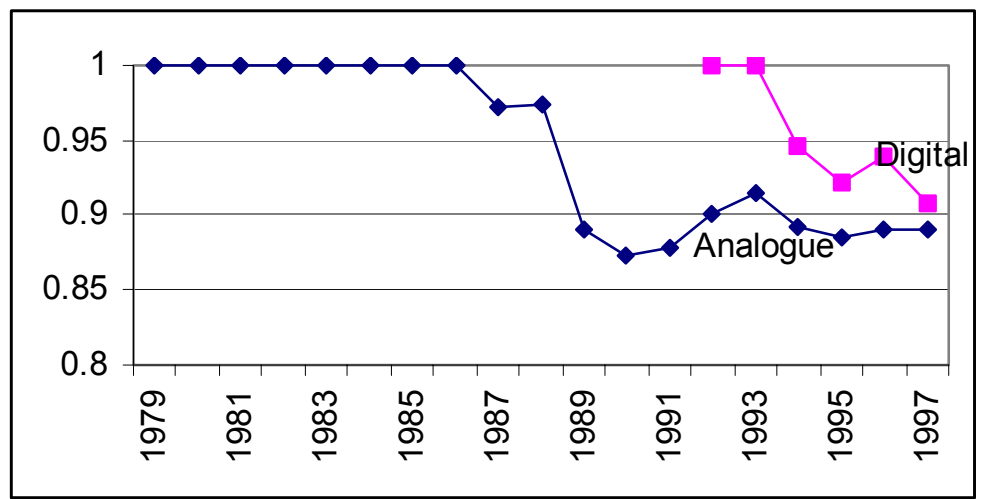

Legenda: The figure indicates the number of countries hat have a single cellular system (standard) of the total adopting countries 
Figure 5.

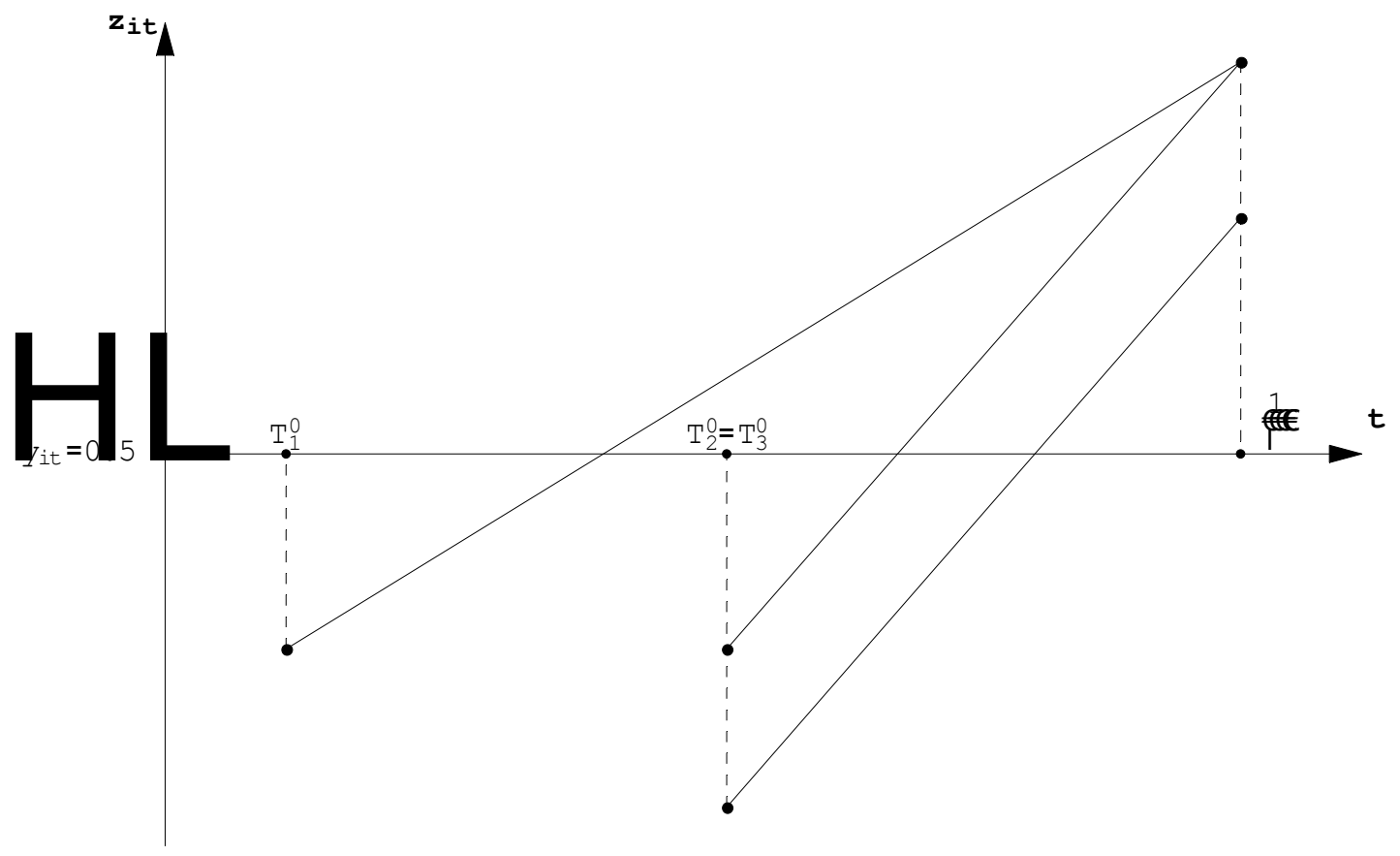

Figure 6. Estimated country-specific fixed effects

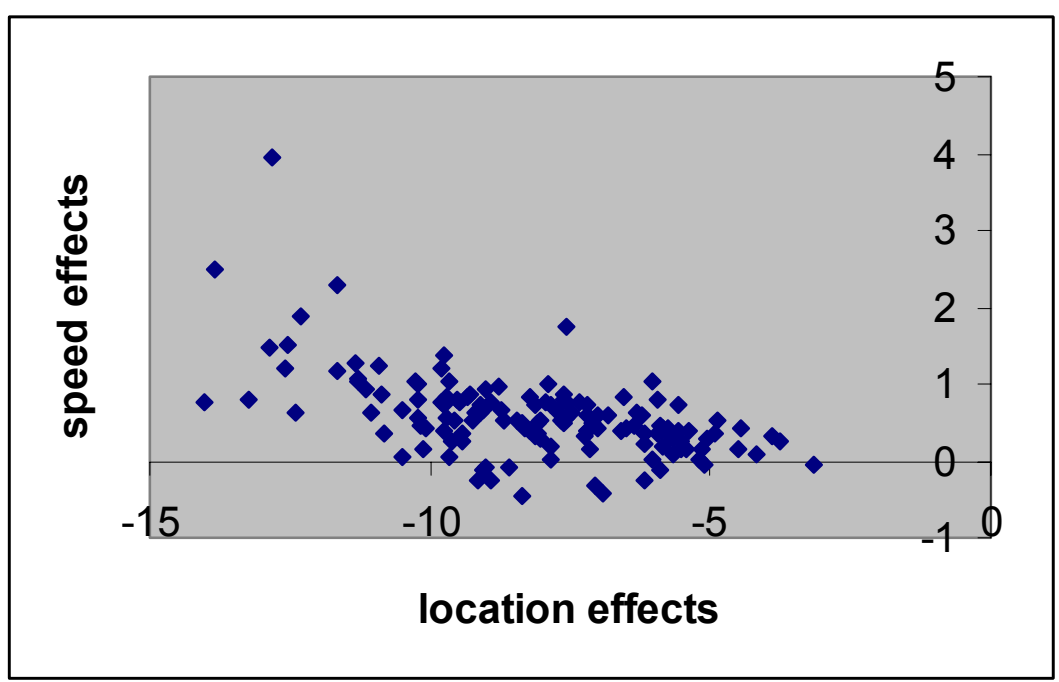

